\section{O Impacto do Ensino Remoto Emergencial na carga de trabalho dos discentes de um curso de Instituição Federal de Educação Superior}

\author{
The Impact of Emergency Remote Education on \\ the workload of students in a Federal Institution \\ of Higher Education course
}

\author{
Marcos Antonio Tedeschi ${ }^{1}$, Faimara do Rocio Strauhs ${ }^{2}$
}

\begin{abstract}
RESUMO
A atual situação imposta trazidas pela pandemia do COVID-19, com a paralização da educação presencial e a utilização emergencial com a implantação do Ensino Remoto Emergencial (ERE) em diversas intuições de ensino, sem estabelecer o mérito e informações sobre cargas cognitivas decorrente desta, fomentou o objetivo desta pesquisa em mensurar a carga de trabalho dos discentes a que se submete os acadêmicos que cursam disciplinas nesta modalidade em uma Universidade Pública do sul do País. A metodologia utilizada foi mista, utilizando levantamento e revisão sistemática da literatura sobre Educação a Distância, Ensino Remoto e Carga de Trabalho, tendo como instrumento o protocolo NASA-LTX, adaptado pelos autores. A coleta de dados foi em nove disciplinas durante o ano de 2020, com 73 discentes participantes. Apoiado pela revisão realizada e os dados levantados concluiu que as disciplinas avaliadas com apresentaram de carga de tarefa subjetiva ou informacional moderada na percepção dos participantes.

Palavras-chave: Educação a Distância (EaD). Ensino Remoto Emergencial (ERE). Carga Cognitiva. Carga Mental. NASA-LTX.
\end{abstract}

\title{
ABSTRACT
}

The current imposed situation brought about by the COVID-19 pandemic, with the paralysis of face-toface education and emergency use with the implementation of Emergency Remote Education (ERE) in several teaching intuitions, without establishing the merit and information on cognitive burdens resulting from this, fostered the objective of this research in measuring the workload of the students to which academics taking courses in this modality are submitted to at a Public University in the south of the country. The methodology used was mixed, using a systematic review and review of the literature on Distance Education, Remote Teaching and Workload, using the NASA-LTX protocol as an instrument, adapted by the authors. Data collection was carried out in nine subjects during the year 2020, with 73 students participating. Supported by the review carried out and the data collected, it concluded that the disciplines assessed with presented a moderate subjective or informational task load in the participants' perception.

Keywords: Distance Education (DE). Emergency Remote Education (ERE). Cognitive Load. Mental Load. NASA-LTX.

\section{RESUMEN}

La actual situación impuesta por la pandemia de COVID-19, con la parálisis de la educación presencial y el uso de emergencia con la implantación de la Enseñanza Remota de Emergencia (ERE) en varias

\footnotetext{
${ }^{1}$ Doutor em Engenharia da Produção-linha de Ergonomia. Professor Associado III da Universidade Federal do Paraná (UFPR), Curitiba, Paraná, Brasil. E-mail: ted@ ufpr.br. Orcid: https://orcid.org/0000-0002-60973280 CV: http://lattes.cnpq.br/8009402349738946.

${ }^{2}$ Doutora em Engenharia da Produção. Professora Titular da Universidade Tecnológica Federal do Paraná (UTFPR), Curitiba, Paraná, Brasil. E-mail: faimara@utfpr.edu.br. Orcid: https://orcid.org/0000-00024013-2724 CV: http://lattes.cnpq.br/3857956905317907.
} 
intuiciones docentes, sin establecer el mérito y la información cognitiva cargas derivadas de ello, propició el objetivo de esta investigación en medir la carga de trabajo de los estudiantes a los que se someten los académicos que cursan cursos en esta modalidad en una Universidad Pública del sur del país. La metodología utilizada fue mixta, mediante una revisión sistemática y revisión de la literatura sobre Educación a Distancia, Enseñanza Remota y Carga de Trabajo, utilizando como instrumento el protocolo NASA-LTX, adaptado por los autores. La recogida de datos se realizó en nueve asignaturas durante el año 2020, con la participación de 73 alumnos. Apoyado por la revisión realizada y los datos recolectados, concluyó que las disciplinas evaluadas presentaban una carga de tareas subjetiva o informativa moderada en la percepción de los participantes.

Palabra-clave: Educación a distancia (ED). Educación Remota de Emergencia (ERE). Carga cognitiva. Carga mental. NASA-LTX.

\section{INTRODUÇÃO}

Em virtude do cenário atual de pandemia e as questões de distanciamento social, a Educação à Distância em sua modalidade de Ensino Remoto passou a ter novo significado no contexto da educação nacional, reafirmando-se como um novo território a ser explorado. Utiliza-se o conceito de ambiente ou espaço educacional associado ao de territorialidade de Albagli (2018, p.28), pois "refere-se, às relações entre um indivíduo ou grupo social e seu meio de referência", "expressando um sentimento de pertencimento e um modo de agir no âmbito de um dado espaço geográfico", neste caso o espaço virtual, na perspectiva que a sociedade modela a ciência e a tecnologia e essas, por sua vez, modelam a sociedade e o ambiente.

Inquestionavelmente, toda atividade humana contém uma carga de trabalho, em particular a carga cognitiva na sua execução, principalmente as educacionais. Contudo, nosso conhecimento sobre as cargas de trabalho e a educação, estão associadas ao território da educação presencial com tempos e espaços delimitados, ficando obscuro as informações sobre as cargas no território virtual da educação.

O problema passa assim em identificar qual o impacto na carga de trabalho discente no Ensino Remoto Emergencial (ERE) de um curso de uma Instituição Federal de Educação Superior (IFES), decorrente do cenário atual de pandemia? Tendo como pressuposto que na ausência do contado humano para produção da comunicação ampla, por diversos estratégia, poderá indicar um aumento da carga de trabalho nesta modalidade de Educação à Distância $(\mathrm{EaD})$.

Justifica-se este estudo pela introdução desta modalidade de ensino com a situação atual imposta trazidas pela pandemia do COVID-19 ou SARS-CoV-2 e a paralização da educação presencial, bem como a falta de estudos sobre carga de trabalho discentes para 
esta modalidade de ensino que nos últimos anos em todas instituições de ensino, de todos os níveis, de forma hídrica ou plenamente a distância, ofertam estas estabelecer o mérito das cargas de trabalho a serem executadas por participantes desde o planejamento, execução até a avaliação.

O objetivo geral estabelecido é de mensurar a carga de trabalho empregada ao acadêmico que cursam alguma disciplina em Ensino Remoto Emergencial de uma IFES.

Logo, apresentando aspecto limitador a uma disciplina na modalidade à distância na forma ERE no curso de Gestão da Informação no Ambiente Virtual de Aprendizagem de uma Universidade Federal do sul do Brasil, no ano de 2020, com 9 (nove) turmas e um com total de 73 (setenta e três) discentes respondentes.

O estudo classificou-se como Pesquisa de Campo de Levantamento de método misto com análise qualitativa/quantitativa, com procedimentos de levantamento bibliográfico de base e localização dos dados diretamente na população alvo. $O$ instrumento aplicado foi o NASA-TLX (Task Load Index, ou Índice de Carga e Tarefa) que é uma ferramenta de avaliação subjetiva, usada para determinar o nível de carga de trabalho, com um procedimento de classificação multidimensional.

A estrutura deste artigo, iniciará com a fundação teórica como uma revisão sobre Educação, Educação à Distância e Carga Cognitiva. Posteriormente a apresentação do método com a descrição do instrumento (NASA-LTX) em apêndice e as características da população abordada, apresentação dos resultados do levantamento encontrados e posterior discussão.

\section{EDUCAÇÃO}

A educação, palavra do Latim educare, que é uma forma derivada de educere que contém a idéia de conduzir. Com a evolução semântica passou a conter aplicação de métodos próprios para assegurar a formação e o desenvolvimento físico, intelectual e moral de um ser humano, traduzindo-se pela mudança de comportamento. (HOUAISS, 2001).

Com uma analogia com a Teoria da Informação originada em 1920 e os trabalhos pioneiros de Leo Szilar e H. Nyquist (CHIAVENATO, 2003), que propõem a qualquer sistema de comunicação conter seis componentes, a saber: Fonte, Emissor ou 
Transmissor, Canal, Receptor, Destino e Ruído, e sendo a educação um sistema de comunicação, se indicaria correlacionar a fonte e o destino como sendo a sociedade, representada pelos diversos tipos de educação dentro da Lei de Diretrizes e Base (LDB). O emissor ou transmissor como o ensino sendo os sistemas adequados e necessários a essa transferência de dados ou informações, o receptor como a aprendizagem, que é adquirir ou reter dados, informações e conhecimento transferidos ou a mudança de comportamento. O canal ou meio, um dos focos deste artigo, como o processo ensinoaprendizagem, onde separa em metade iguais duas partes em tempo síncronos ou assíncronos e espaços, onde temos as educações presenciais, à distância e hibridas, como representadas na figura abaixo.

Figura 1 - O Sistema Educacional através da Teoria da Informação

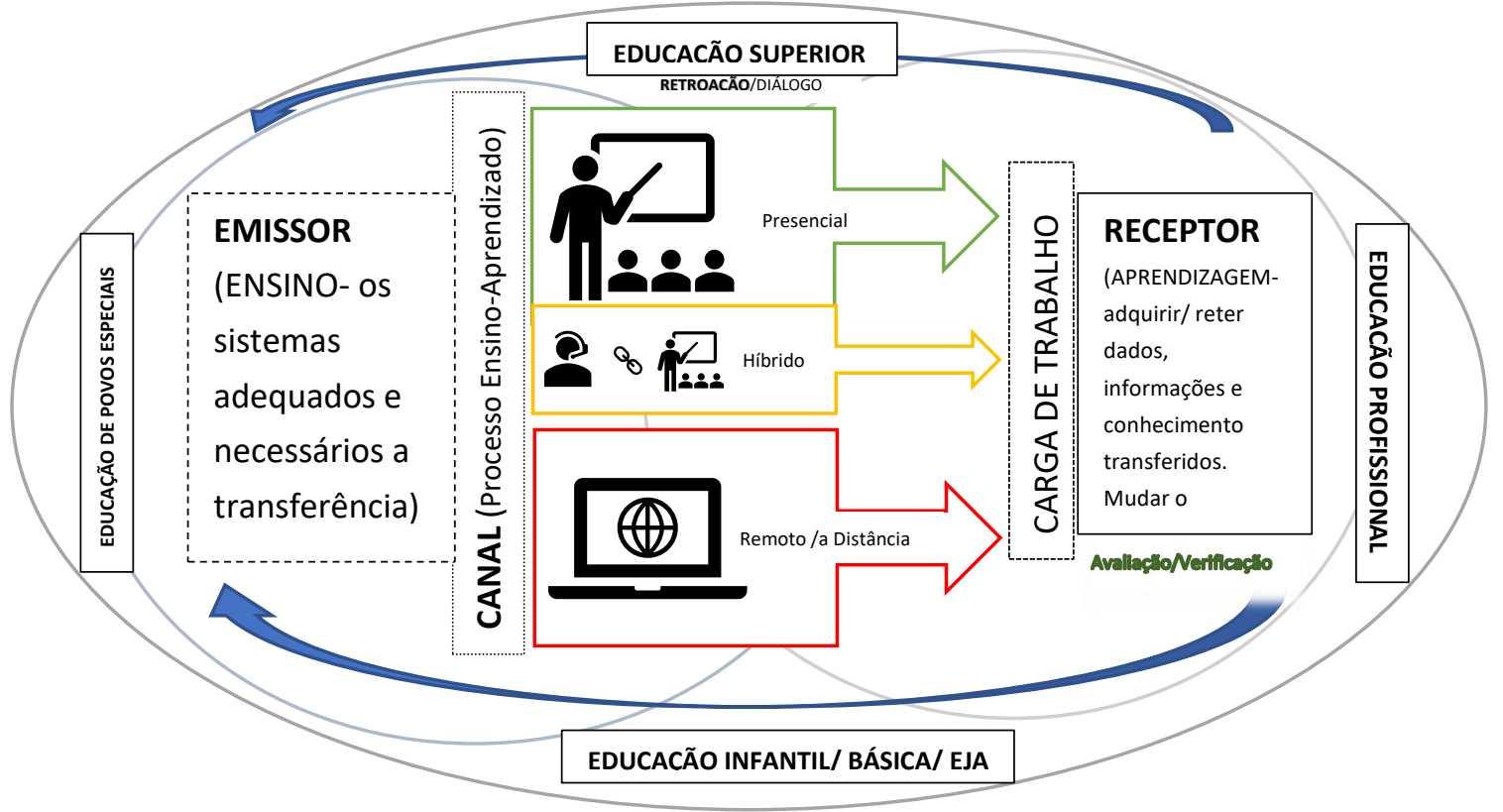

Fonte: Autores (2021).

Toda discussão está neste contexto, pois não está nem na palavra educação, muito menos na palavra ensino, mas sim no processo ensino-aprendizado ou simplesmente no meio ou canal utilizado, bem como no possível componente conhecimento e seus ruídos, aqui representado pelas cargas de trabalho que pode conter diversos vieses, desde motivações, capacidades tecnologias e financeiras, tempo, cognição, entre outros.

Tradicionalmente a educação é originalmente presencial, termo que está para um dado momento, no mesmo local ou recinto em que acontece um evento. Mas, com o advento da escrita esta pode ser realizada à distância, ou seja, em tempo e local diversos. 
Assim, a Educação à Distância sempre existiu, mas o que está em constante desenvolvimento é o tipo de tecnologia empregada.

A questão se desloca para o meio de comunicação (comum ação entre docente e discente), que inicialmente era presencial síncrona e agregou cartas e livros e/ou apostilas, incluiu telefones, rádios e televisões, posteriormente todos os anteriores acrescentou o telefacsimile e com as novas tecnologias da informação e comunicação (TIC) pode fornecer os processos educacionais de forma remota em espaço distante com ao auxílio de computadores, notebooks, tablets, smartphone entre outros interligados pelos sistemas de comunicações instantâneas de longas distâncias, conhecidas como internet.

\section{EDUCAÇÃO À DISTÂNCIA (EaD)}

A Educação a Distância é uma modalidade de Educação trazida pela Lei $n^{\circ}$ 9394/96, anteriormente intitulada Ensino à Distância, cada vez mais difundida e utilizada na Educação Superior, sendo conceituada pelo Ministério da Educação (BRASIL. Portal MEC, 2020) como "a modalidade educacional na qual alunos e professores estão separados, física ou temporalmente e, por isso, faz-se necessária a utilização de meios e tecnologias de informação e comunicação". Contudo, a qualidade dela ainda é questionável, pois os critérios avaliativos e metodológicos na nova modalidade têm como base a Educação presencial.

Sabe-se que a regulamentação desta modalidade tem início na Lei n 9394/96 a partir do Art. 80 e na Resolução CNE/CES nº 1 de 11/03/2016 para cursos de Educação Superior na Modalidade a Distância. Já para os cursos presenciais que pretendem ofertar parte de suas disciplinas nesta modalidade, a regulamentação estabeleceu o limite de $20 \%$ da carga total do curso nesta modalidade através da Portaria MEC n 4.059 de 10/12/2004, Art. $1^{\circ} \S 2^{\circ}$ e recentemente ampliou a possibilidade desta oferta da modalidade à distância para 40\% com a Portaria MEC 2.117/2019 de 6/12/2019 Art. $2^{\circ}$.

A Educação a Distância é uma modalidade de ensino e aprendizagem que requer vontade, querer e em síntese a disciplina do discente, requerendo saber estudar sozinho, tornar-se um ser humano autônomo, crítico e formador de opinião (SANTANA; GIRAFFA, 2018).

Outrossim, a EaD e suas tecnologias surgiram para consistir em programas que auxiliassem a educação brasileira (educação presencial). Tendo como primeira tendência, a legal concebida, a partir da LDB, para ocupar-se de todos os níveis da escolarização, 
que consistiu em grande mercado educacional na Educação Superior em atuar com prioridade nos cursos de graduação. A segunda tendência foi da iniciativa privada com oferta extraordinária de vagas de forma mais expressiva do que já fez com a educação presencial e a terceira tendência, que a EaD sob o patrocínio privado, concentrar-se-ia nos cursos de poucos investimentos em laboratórios e materiais pedagógicos, voltados para segmentos populares da sociedade. Contudo, em todo curso à distância se coloca como concorrente da educação presencial (GIOLO, 2018).

Por isso a Educação a Distância revela-se para Educação Superior como forma para o contexto da mundialização financeira, e no panorama brasileiro como mecanismo democratizante (PAULA, 2016). Mas com grande preocupação com sua grande evasão (RIEDNER; BATISTA, 2018).

Nesta linha Coelho e Tedesco (2017, p.617) tem posição de quanto maior o nível de presença social, maior a interação e percepção de aprendizagem dos atores envolvidos, bem como a maior a familiaridade com o ambiente virtual reduzirá a evasão e melhora a avaliação final do discente na $\mathrm{EaD}$.

Indubitavelmente a EaD é dual, constituída de aspectos positivos e negativos. Fernandes (2018) apresenta os principais pontos:

a) Principais aspectos positivos; Velocidade e abrangência de ensino pelas mídias eletrônicas. Flexibilidade e personalização do modelo de ensino. Possibilidade de ensino sem a presença física entre aluno e professor. Minimização de deslocamentos. Maior possibilidade de inclusão. Facilidade de acesso, economia de tempo e ritmo individual de ensino. Aprendizagem ativa e autonomia. Potencial para inovação. Facilidade de interação e participação. Menor custo financeiro. Inovação.

b) Principais aspectos negativos: Ausência de atualizações dos programas pelas instituições. Baixo prestígio. Falta de preparo na organização dos projetos pilotos, ausência de divulgação dos projetos, descontinuidade dos programas sem prestar esclarecimentos. Deficiência nos processos avaliativos. Falta de comprometimento dos alunos. Dificuldade de discussão.

Ancorando a essas reflexões, faz-se necessário entender que a $\mathrm{EaD}$, é tanto a multiculturalidade quanto a multimodalidade e, portanto, um multiletramento que se destaca com a chegada de novas tecnologias de informação, alcançando para todas as regiões do país, agregando culturas diversas e diversos territórios em diferentes linguagens (NANTES, 2019). 
Assim, como aborda Bohadana e Valle (2009, p. 555), a "desterritorialização" da educação presencial anuncia a sua desconstrução com acelerações muitas rupturas inevitavelmente, pois as bases antropológicas da EAD está de frente a duas figuras da modernidade, a revolução do tempo e espaço. E concluem seus estudos interrogando (p.563); "se o sujeito conectado e o ciberespaço não são, a rigor, a manifestação paroxística dos vícios que a modernidade não soube evitar”.

De fato, as tecnologias digitais alteraram os processos na atualidade, gerando novos modos de produzir, transmitir, receber e conservar a informação, e a cultura é influenciada por esse mundo dinâmico, virtual, em rápida mutação. (VELOSO; BONILLA, 2018, p. 11). De maneira geral, a presença de plataformas digitais amigáveis ao usuário não criam satisfação, mas a sua ausência traz insatisfação, mais os resultados são decorrentes de fatores comportamentais e técnicos, como; a motivação hedônica, a autoeficácia e, em especial, a qualidade do sistema, para a retenção de usuários em cursos EaD (MONDINI; DOMINGUES, 2018, p.21).

Por consequência, pontuam Veloso e Bonilla (2018: p. 20) que a emergência das ideias depende: "da dinâmica organizacional e institucional dos cenários educacionais, da mobilização afetiva e cognitiva em ambientes propícios e motivantes que possibilitam a reflexão e os meios para que os sujeitos interajam entre si e com diferentes elementos culturais".

Mas qual é a diferença entre o ensino remoto, ensino à distância e a educação à distância? Estas diferenças são apresentas a seguir.

\subsection{Ensino Remoto x Ensino à distância e Educação à distância}

Historicamente o termo era Ensino à Distância, o qual era planejado para a transmissão de dados ou informações das diversas modalidades educacionais de forma síncronas (no mesmo tempo e espaços diferentes) ou assíncronas (em tempos e espaços diferentes), aproveitando a tecnologia existente, mas sem uma regulamentação oficial.

Com a Lei 9394 de 20/12/1996 (LDB) explicitou no corpo textual do art. 80 a regulamentação desta modalidade de ensino, a saber: "Art. 80. O Poder Público incentivará o desenvolvimento e a veiculação de programas de ensino a distância, em todos os níveis e modalidades de ensino, e de educação continuada". Mas, no Decreto 9.057, de 25/03/2017 que regulamentou este artigo em epígrafe, implantou o termo Educação à Distância, criando uma confusão de termos. 
Com o exposto, em questões oficiais os termos educação e ensino à distância são análogos. Contudo para o ANDES-SN (Sindicato Nacional dos Docentes das Instituições de Ensino Superior, p.08) a Educação à Distância não se reduz às atividades de ensino, mas para um efetivo processo educativo exige-se:

(1) dimensões formativas essenciais, como a produção crítica e criativa do conhecimento;

(2) a vivência que possibilita o diálogo entre educador e educando, assim como a interlocução entre diferentes áreas do conhecimento;

(3) a experimentação de pesquisa, extensão, monitoria e outras ações políticopedagógicas, possíveis apenas na modalidade presencial.

No contexto da pandemia, o termo "Ensino Remoto" se popularizou. O isolamento social, necessário para impedir a expansão da infecção por COVID-19, fez com que as atividades presenciais nas instituições educacionais deixassem de ser o "normal" ou presencial. Por isso, as instituições educacionais passaram a utilizar de forma generalizada estratégias de $\mathrm{EaD}$.

O problema é que, para manter as atividades regulares funcionando na "nova normalidade" criada pela pandemia de COVID-19, muitas instituições, especialmente do setor privado, começaram a utilizar estratégias que violavam a legislação vigente, utilizando um eufemismo: o ensino remoto. Outros nomes mais pomposos também foram utilizados para ocultar o processo de imposição de arremedos de EaD: Ensino por meio de Tecnologias Digitais de Informação e Comunicação (TDIC), Calendário Complementar, Estudo Remoto Emergencial e outros.

Dentre as atividades pedagógicas não presenciais, o Parecer do Conselho Nacional de Educação (CNE/CP n ${ }^{\circ}$ 9/ 2020) apontou como caminho o ensino remoto, utilizando para isso as tecnologias de informação e comunicação (TICs). Essa alternativa desconsidera e aprofunda as desigualdades sociais e econômicas dos sujeitos, pois para que haja as atividades remotas é necessário o acesso, tanto dos alunos quanto dos professores, a uma série de aparatos técnico-tecnológicos como, computadores e/ou smartphones, internet com conexão estável e rápidas, ambiente doméstico silencioso e confortável ou ergonômicos. Nem de longe esses requisitos estão ao alcance da maioria dos docentes e discentes das escolas públicas brasileiras.

Nesta pesquisa, optou-se pelo termo ensino remoto emergencial utilizado na IES pesquisada e proposto por António Moreira e Schlemmer (2020, p.9) onde o Ensino Remoto de Emergencial (ERE) é um modelo de ensino temporário devido às 
circunstâncias desta crise sanitária, envolvendo soluções de ensino totalmente remotas idênticas às práticas dos ambientes físicos, com objetivo principal nestas circunstâncias não de recriar um ecossistema educacional online robusto, mas sim fornecer acesso temporário e de maneira rápida durante o período de emergência ou crise.

\subsection{Características do Ensino Remoto Emergencial (ERE)}

Com base no Parecer do Conselho Nacional de Educação (CNE/CP) nº 9/ 2020) o ERE foi a transposição de todos níveis educacionais para o meio digital, que segundo Oliveira et al. (2020, p. 27-28) "exige que gestores, coordenadores e professores se posicionem e ajam na intenção de adaptar conteúdos curriculares, dinâmicas de sala, até avaliações, visando dar continuidade as aulas", tendo como principais provocações por Ludovico et al. (2020) a definição dos recursos que serão utilizados como os tipos de comunicação, síncrona ou assíncrona; o tempo de cada atividade; a faixa etária dos discentes; a escolha de trabalhar novos conteúdos ou fazer revisões do que foi visto.

A provocação inicial está para que professores sejam formados com conhecimento técnico-pedagógico, segundo Haviaras (2020), a fim de estarem preparados para desenvolver estratégias metodológicas amparados no uso das ferramentas tecnológicas. Corrobora neste plano Santos e Dias-Trindade (2020), em relação a mediação pedagógica online, indicando as necessidades dos professores desenvolverem competências digitais necessárias para gerar reflexões críticas nas ações e técnicas utilizadas. Ainda Carmo e Franco (2020), defendem que neste novo ambiente da sala de aula online exige do docente competências e saberes orientados para o desenvolvimento de seu trabalho com organização, correção, presteza, cordialidade e sensibilidade; fatores necessários a criação e manutenção de um ambiente de interfaces tecnológicas educacionalmente propício.

Lima, Queiroz e Sant'anna (2018) explicitam que geralmente as aulas são organizadas para uma aula/apresentação expositiva, onde o professor explica, lê slides, dificultando assim a participação e a interação dos estudantes, convidando explicitamente o educando para ouvir e calar. Mas, cada discente tem a sua forma de aprender, ou seja, possuem estilos de aprendizagem diferentes.

Citam ainda Lima, Queiroz e Sant'anna (2018, p.9) que os discentes de características visuais, aprendem mais facilmente, quando veem palavras escritas, tendo importância fulcral o desenvolvimento nestes o hábito de escrever (não digitar), fazer anotações das palavras do professor, referências, resumos, tabelas, esquemas, desenhos, 
fluxogramas, gráficos, mapas mentais, fichas de apoio, resenhas, folhetos, portfólios, uso de vídeos ou apresentações audiovisuais. Nos discentes de características auditivas apresentam-se muito organizados e metódicos, apreciando as exposições orais e aprendem mais concentrados em ouvir, com interação com a classe mais lenta para processar a informação e contribuir simultaneamente, gostando de explicar os temas estudados para os colegas. Já os discentes de características cinestésicas são centrados em si mesmos, sempre mexendo em algo que tenham à mão, precisando de movimentação corpórea, tendo que interagir sempre com a necessidade de manipular materiais, ao mesmo tempo em que a visualização e estímulos auditivos devem estar sincronizados, possuem padrões de praticidade e necessidade der envolvimento e experimentações com tendência a se dispersar senão se sentirem envolvidos no assunto.

Assim, o “ensino remoto emergencial” são atividades síncronas e assíncronas que meramente permitem, sem nenhum apoio pedagógico ou qualquer estrutura adequada, a transposição de aulas presenciais para virtuais. O resultado é a mera "digitalização" das aulas presenciais em vídeos de longa duração, compartilhamento de apresentações em PowerPoint de aulas e textos online que seriam indicados para leitura no formato presencial, assumindo-se como "a mesma coisa", bem como calendários de semestres/períodos especiais, virtuais, complementares, entre outros que seguem a mesma lógica do calendário presencial.

Preocupações com qualidade da educação, inclusão social e igualdade de acesso são secundarizadas e convertidas em problemas meramente técnicos, não abordando as cargas que as tarefas já impostas. Quando isso ocorre, os discentes acabam sendo desestimulados, pois perdem o interesse, foco e a atenção e aumenta a carga cognitiva a ser suportada, já que não atende a sua forma de aprender, gerando em muitos casos a evasão destes.

Essa alternativa, embora não havia outra no momento, desconsidera e aprofunda as desigualdades sociais e econômicas dos sujeitos, pois para que haja as atividades remotas é necessário o acesso, tanto dos discentes quanto dos docentes, a uma série de aparatos técnico-tecnológicos como, computadores e/ou smartphones, programas específicos e treinamento, internet com conexão estável, ambiente doméstico silencioso e ergonômico. Nem de longe esses requisitos estão ao alcance da maioria dos docentes e estudantes das escolas públicas brasileiras.

Será apresentado a seguir os conceitos de carga de trabalho e sua ação no processo ensino-aprendizado para obter a relação com o ERE. 


\section{CARGA COGNITIVA}

A carga, por metonímia, é aquilo pode ser suportado pela pessoa ou ainda, a pressão exercida em um objeto em repouso ou em movimento (HOUAISS, 2001). A carga neste artigo é considerada uma relação funcional entre as exigências do trabalho constituída em termos de estímulos fisiológicos, ambientais, psicológicos e sociais e a capacidade de resposta biológica e psicológica às exigências, bem como a sua capacidade de adaptação orgânica. (CRUZ; FRUTUOSO, 2005)

Já a cognição é o efeito de conhecer ou processo de adquirir um conhecimento. $\mathrm{Na}$ Psicologia têm-se que é o conjunto de unidades de saber da consciência com base em experiências sensoriais, pensamentos e lembranças. (HOAUISS, 2001). Se refere aos processos de interpretação e significação destas sensações organizadas (WISNER, 1994). Cognição é conhecimento em processamento ou construído, envolvendo percepção, raciocínio, pensamentos, linguagem, entre outros. (SCHULENBURG; PEZZINI, 2013: p. 208 e 212)

Em Santos, Moser e Lima (2019, p.802) a carga cognitiva é atribuída pelas informações coletadas em certo instante pela memória de trabalho. Esta capacidade de coleta e processamento é individualizada e têm influência na memória de longo prazo a qual determina a aprendizagem. Portanto, a expressão carga cognitiva não se refere ao volume de informações a serem aprendidas pela memória de trabalho ou primária, mas a demanda ou exigência que essas informações produzem esta memória em determinado indivíduo.

Pontua Souza (2010: p.42 e 51) que se a capacidade da memória da primária é menor do que a requerida pela aprendizagem, esta carga cognitiva excessiva imposta à memória primária comprometerá a aprendizagem, bem como excesso de integração de informações redundantes aumenta a carga cognitiva com diminuição do aprendizado.

A ISO 10075-1: 2017 (ABNT, 2017), define os princípios ergonômicos relacionados à carga de trabalho mental em seus termos e definições gerais, de qualquer atividade, até mesmo a predominantemente física, que pode impor estresse mental. $\mathrm{O}$ termo "Stress mental" ou estresse mental acontece quando ocorre qualquer influência externa que atinge os seres humanos e que lhes afeta mentalmente, gerando aumento ou diminuição do esforço metal. Nesta Norma Internacional a expressão "mental" refere-se 
ao cognitivo, processos de conhecimentos e inter-relacionadamente com os emocionais nos seres humanos.

Soares e Mager (2020: p.65), corroboram ao expor que toda atividade realizada demanda algum processo cognitivo com tipos específicos de processos, como: a atenção que permite a concentração e habilidade de focar em algo desejado, mesmo com diversas interferências; a percepção e reconhecimento referente a como a informação é adquirida do ambiente pelos diferentes sentidos; a memória e aprendizado que implica recordar os vários tipos de conhecimentos.

$\mathrm{Na}$ atualidade, o contexto do trabalho informatizado resulta em sobrecarga, tanto física como mental, pois o desgaste é predominantemente cognitivo, dada a quantidade de capacidades e saberes que requer. Uma carga mental elevada também pode ser observada nas situações complexas, quando numerosas tarefas interagem como no trabalho com TI (Tecnologia da Informação) que requer maior exigência cognitiva e, por conseguinte, é maior a sobrecarga em seus processos mentais. (MENEZES, 2016: p.118, 120 e 122)

Para melhor compreensão surge a Teoria da Carga Cognitiva que fora delineada entre 1976 e 1998, pelo psicólogo Australiano John Sweller ao investigar como a execução de tarefas complexas afeta a aprendizagem. Esta teoria estabelece a existência de três carga cognitiva; a estranha ligada ao formato da apresentação, a intrínseca ligada ao conteúdo e a relevante ligada a variabilidade (ZAMBRANO, 2018).

A medição da a Carga Cognitiva apresenta três diferentes técnicas, a saber: autoavaliações feitas por meio de questionários, técnicas das medidas fisiológicas e a das tarefas secundárias (ZAMBRANO, 2018: p. 59 e 86). A mais utilizada relatada em revisão de literatura é a técnica da autoavaliação, a qual será utilizada neste estudo através do instrumento NASA/LTX.

A teoria da carga cognitiva é uma teoria que pode ajudar os profissionais da educação a projetar os territórios de aprendizado apropriados, pois leva em consideração as limitações da memória de trabalho dos discentes. Assim, sugere-se considerar esta teoria como uma estrutura que orienta as decisões, o design e a prática educacional, a fim de torná-la mais eficaz e eficiente. (ZAMBRANO, 2018)

Em fecho, Silva Filho (2008: p. 12) relata haver poucas dúvidas em relação aos impactos produzidos pela internet e os meios eletrônicos no processo de ensino, sobretudo no ensino à distância (EAD). Tendo a preocupação central em adequar a aplicação dos softwares, do conteúdo e da variabilidade como preceitos da ergonomia cognitiva, 
estando subdividida em duas dimensões para fins de análise: a brevidade (uso de ações mínimas e concisão) e densidade informacional, para minimizar as cargas cognitivas dos educandos.

\section{METODOLOGIA}

Esta foi uma Pesquisa de Campo com Levantamento de método misto com análise qualitativa/quantitativa, com procedimentos de levantamento bibliográfico para fundamentação teórica e localização dos dados diretamente na população alvo.

A pesquisa de levantamento é muito usada em pesquisas descritivas por ter como principal característica a interrogação direta das pessoas cujo comportamento se deseja conhecer para uma análise quantitativa a fim de obter-se conclusões sobre as indagações (CAJUEIRO, 2015); (BENACHIO; MENDONÇA; NASCIMENTO, 2019).

Cita Oliveira (2018, p.39 e 67) que a pesquisa descrita qualitativa possui ambiente natural com fonte direta de dados, representada aqui pelas nove turmas pesquisadas ofertadas no Ensino Remoto Emergencial no primeiro e segundo semestres do ano 2020, durante a suspensão do calendário oficial da IFES; com caráter descrito em que o estudo narra o que acontece, analisando fatos/fenômenos permitindo uma análise do problema de pesquisa de qual seria a carga cognitiva nestas disciplinas, em relação a diversos aspectos; básicas; o significado que as pessoas dão às coisas e o enfoque indutivo.

$\mathrm{Na}$ verdade, a pesquisa de levantamento social é um dos muitos tipos de pesquisa social (GIL, 2017) que, como todos os outros, apresenta vantagens e limitações. Dentre as principais vantagens dos levantamentos estão o conhecimento direto da realidade, a economia célere e quantificação com os dados levantados e agrupados em tabelas e gráficos. Contudo, deve-se destacar as principais limitações dos levantamentos, como a ênfase nos aspectos perceptivos, que são dados subjetivos, podendo gerar distorções; a existência da pouca profundidade no estudo da estrutura e dos processos sociais; e limitação da apreensão do processo de mudança, o qual gera uma visão estática do fenômeno estudado.

Considerando as vantagens e limitações, os levantamentos são mais adequados para estudos descritivos que explicativos. São úteis para o estudo de opiniões e atitudes, foco desta pesquisa, porém pouco indicados no estudo de problemas referentes a relações e estruturas sociais complexas. (GIL, 2017, p. 52) 


\subsection{População da pesquisa}

A população da pesquisa são 9 (nove) turmas do curso de graduação de Gestão da Informação na forma Ensino Remoto Emergencial no Ambiente Virtual de Aprendizagem de uma Universidade Federal do sul do Brasil no primeiro (ERE1) e segundo (ERE2) semestres de 2020, em virtude da suspensão do calendário oficial em decorrência da decretação do estado de pandemia por COVID-19, com um total de respondentes de 73 (setenta e três). Em conformidade com o quadro abaixo:

Quadro 1 - Quantitativo de educando nas disciplinas ofertadas nos Ensinos Remotos Emergenciais (ERE1 e ERE2) pesquisados em 2020.

\begin{tabular}{|l|c|c|c|c|c|c|}
\hline Disciplinas & Matriculados & Aprovados & Repr. Faltas & Repr. Notas & Respondentes & $\%$ Ap \\
\hline SINY8Y ERE2 & 20 & 16 & 4 & 0 & 4 & $25 \%$ \\
\hline SINY3Y ERE1 & 30 & 24 & 6 & 0 & 12 & $50 \%$ \\
\hline SINY4YERE2 & 30 & 25 & 4 & 1 & 15 & $60 \%$ \\
\hline SINY2Y ERE1 & 13 & 10 & 3 & 0 & 3 & $30 \%$ \\
\hline SINY0Y ERE1 & 2 & 2 & 0 & 0 & 2 & $100 \%$ \\
\hline SINY9YERE1 & 30 & 22 & 7 & 1 & 12 & $55 \%$ \\
\hline SINY7YERE2 & 20 & 17 & 3 & 0 & 9 & $53 \%$ \\
\hline SINY6YERE1 & 37 & 15 & 18 & 4 & 8 & $53 \%$ \\
\hline SINY6YERE2 & 24 & 11 & 13 & 0 & 8 & $73 \%$ \\
\hline TOTAL & 206 & 142 & 58 & 6 & 73 & $52 \%$ \\
\hline & $100 \%$ & $69 \%$ & $28 \%$ & $3 \%$ & $36 \%$ & \\
\hline
\end{tabular}

Fonte: Autores (2021)

Cabe identificar que houveram 206 (duzentos e seis) discentes matriculados no conjunto das 9 (nove) disciplinas pesquisadas no período, sendo 58 (cinquenta e oito) discentes ou 28\% Reprovados por Falta por abandono e 6 (seis) discentes Reprovados por Notas por não realização da tarefas ou $3 \%$, os quais foram respondentes, embora fora enviado o instrumento de pesquisa.

Dos 142 (cento e quarenta e dois) aprovados ou 69\% 73 (setenta e três) responderam o instrumento de forma voluntária, gerando percentuais de análise, ou seja, participaram da pesquisa $52 \%$ dos aprovados ou $36 \%$ dos matriculados nas disciplinas em análise.

\subsection{Caracterização do território da população}

O Estudo foi realizado na Universidade Federal do sul do Brasil em um curso de Gestão da Informação, em decorrência do fácil acesso as informações dos participantes da pesquisa e porque os mesmos tem familiaridade com planejamento e execução de pesquisa sobre ofertas e demandas de informação através de Tecnologias da Informação 
e Comunicação (TICs), definição de políticas de monitoramento, tratamento, uso e segurança da informação entre outros.

Assim, o curso fora instituído com disciplinas em diversas modalidades de ensino, como: plenamente presenciais, plenamente à distância e hibridas com 20\% e 50\% na modalidade à distância de suas cargas horárias estabelecidas, sofrendo adaptação para a oferta de disciplinas de forma totalmente remota síncrona e assíncrona.

O ambiente virtual e aprendizagem (AVA) foi o MOODLE (Modular ObjectOriented Dynamic Learning Environment), software livre de apoio à aprendizagem, executado num ambiente virtual e adotado nas instituições federais brasileiras, o que gerou a possibilidade do fácil acesso aos dados e na geração de cruzamento de todos os conhecimentos de um curso e com maior impacto em questões cognitivas via esta plataforma utilizada nas Universidades Federais com habitualidade.

Fora estabelecido como território de análise de mensuração de carga, 9 (nove) disciplinas do primeiro a oitavo período obrigatórias e optativas, a quais tiveram seus planos de ensino adaptados para ensino plenamente remoto (ERE1-periodo de 27 jul. 2020 a 26 set. 2020 e ERE2- período de 02 nov. 2020 a 23 jan. 2021) com aulas síncronas e assíncronas. As avaliações relativas as frequências e conteúdo, foram através das postagens das tarefas planejadas referentes aos conteúdos programáticos ministrados.

\subsection{Instrumento da pesquisa}

Para a escolha dos instrumentos de pesquisa, utilizou-se o NASA-TLX (Task Load Index, ou Índice de Carga e Tarefa) para coletar avaliações de carga de trabalho subjetivas que foi desenvolvido em 1986 pelo Human Perform Group do NASA AMES Research Center (HART; STAVELAND ,1988), pois já estava traduzido e convalidado pela Universidade de Brasília (UnB). E com base em Alchieri e Cruz (2003), questionários fechados permitem ao avaliador estruturar como quer receber os dados da população e a mesma tem preferência por esse modelo por ser mais fácil e prático de ser respondido.

Como cita Yuliani e Tambunan (2018) o NASA-TLX é uma ferramenta de avaliação subjetiva, usada para determinar o nível de carga de trabalho, com um procedimento de classificação multidimensional. Os resultados são o valor geral da carga de trabalho com base em seis escalas, nomeadamente carga mental, carga física, pressão do tempo, satisfação no trabalho, nível de esforço e nível de estresse.

Em revisão sistemática de literatura sobre métodos de avaliação da carga de trabalho mental, Silva (2018) encontrou 22 ferramentas, destacando-se o método de 
análise de medidas fisiológicas e a ferramenta de análise subjetiva NASA-TLX, os quais juntos representaram praticamente $67 \%$ das aparições, o que reforça a utilização deste instrumento.

O NASA-TLX (1986) consiste na pontuação da carga de trabalho subjetiva baseada na média ponderada de avaliações de seis subescalas, sendo 3 demandas impostas ao sujeito: Demanda Mental, Demanda Física e Demanda Temporal; e 3 dimensões referem-se à interação entre sujeito e tarefa: Desempenho, Esforço e Frustração. Para calcular a carga de trabalho subjetiva, são necessárias duas etapas consistindo na avaliação de peso e de taxas. No apêndice encontra-se os instrumentos já adaptado a população requerida para observação e análise.

Para identificar os pesos, são feitas 15 combinações entre os 6 fatores dois a dois. Assim, cada fator poderá receber de zero a cinco pontos. Para identificar a magnitude dos fatores, é apresentado ao indivíduo, uma régua dividida em 20 intervalos, sendo a cada um, atribuído o valor de 0,5 pontos, totalizando 10 pontos em toda a régua de forma oculta. O indivíduo deve marcar na régua, qual a posição que ele considera de acordo com a carga sofrida na atividade que lhe foi atribuída. Considerando da esquerda para a direita a contagem de zero (0) a dez (10). O cálculo da carga de trabalho de cada pessoa é computado multiplicando a taxa pelo peso, em cada fator. A soma das taxas ponderadas é dividida por 15 (soma dos pesos).

O NASA-TLX por ser instrumento multidimensional produz uma taxa de procedimento onde existe uma pontuação de Carga de Trabalho Global ou Carga Informacional, com base em média ponderada das avaliações obtida em seis subescalas ou níveis, apresentadas e descritas na continuidade deste.

\section{RESULTADOS E ANÁLISE}

\subsection{Processo de coleta de dados e tratamento dos resultados}

A estratégia de aplicação do instrumento NASA/LTX foi de realizar via formulário eletrônico no Google Forms ao final das disciplinas, mais especialmente após a última avaliação, pois de acordo com Fachim (2006), a coleta de dados deve ser efetuada diretamente na fonte de informação. O processo de coleta de dados iniciou-se com a apresentação da proposta do estudo e conscientizando os discentes de que suas respostas seriam para fins acadêmicos e aprimoramento da disciplina e mantidas sobre sigilo. Essa abordagem é justificada por Fachim (2006), ao indicar que em pesquisas diretas deve ser 
feita com cautela, sendo necessário adaptar-se ao ambiente, costumes e cultura para deixar o pesquisado sempre a vontade de participar ou não.

O modo operativo consistiu em após a entrega (postagem) da última avaliação o discente era encaminhado através do recebimento de link (endereço eletrônico), onde era acessado o instrumento de pesquisa com orientações de preenchimento e sem identificação para garantir o anonimato. Após os resultados eram lançados automaticamente em uma planilha Excel afim de produzir a tabulação e apresentação dos resultados.

\subsection{Resultados encontrados}

Como resultado da coleta tem-se as taxas médias encontradas apresentadas na tabela e gráfico 1, a apresentação dos pesos médios encontrados na tabela e gráfico 2 e por fim, o cálculo da média ponderada da carga da tarefa na tabela 3.

Tabela 1 - Taxas dos esforços e níveis médios na produção da carga da tarefa realizada

\begin{tabular}{cc}
\hline Taxas & Intervalo 0 a 10 \\
\hline Esforço Mental (EM) & 5,83 \\
\hline Esforço Físico (EF) & 4,84 \\
\hline Esforço Temporal (ET) & 5,26 \\
\hline Nível de Realização (NR) & 6,26 \\
\hline Nível de Esforço (NE) & 6,08 \\
\hline Nível de Frustração (NF) & 4,20
\end{tabular}

Fonte: Autores (2021).

O resultado da coleta referente as taxas de esforços e níveis médios apresentou três grupos distintos, sendo o primeiro com valor maior que seis para o nível de realização e esforço para a execução das disciplinas em ensino remoto; um grupo intermediário superior a cinco pontos para o esforço mental e temporal e um grupo com pontuação inferior a cinco composto da exigência física e nível de frustração.

Tabela 2 - Pesos dos esforços e nível médios na produção da carga de trabalho

\begin{tabular}{cc}
\hline Pesos & Total 15 \\
\hline Esforço Mental (EM) & 3,61 \\
\hline Esforço Físico (EF) & 1,32 \\
\hline Esforço Temporal (ET) & 2,45 \\
\hline Nível de Realização (NR) & 3,47 \\
\hline
\end{tabular}




\begin{tabular}{cc}
\hline Nível de Esforço (NE) & 2,84 \\
\hline Nível de Frustração (NF) & 1,31 \\
\hline
\end{tabular}

Fonte: Autores (2021).

Para o resultado da coleta referente aos pesos médios, também é encontrado três grupos distintos, contudo o primeiro com valor maior que três para a exigência mental e nível de realização como significativos para a execução das disciplinas em ensino remoto; um grupo intermediário superior a dois pontos o esforço temporal e nível de esforço e um grupo com pontuação inferior a dois pontos composto das exigência física e nível de frustração como significativos na execução das disciplinas participantes.

Tabela 3 - Apuração da carga das tarefas na execução das disciplinas ofertadas e elencas através de Ensino Remoto Emergencial, segundo o protocolo NASA/LTX

\begin{tabular}{cc}
\hline Esforços e Taxas & Pesos X Taxas \\
\hline Esforço Mental (EM) & $3,61.5,83=21,0463$ \\
\hline Esforço Físico (EF) & $1,32.4,84=6,3888$ \\
\hline Esforço Temporal (ET) & $2,45.5,26=12,887$ \\
\hline Nível de Realização (NR) & $3,47.6,26=21,7222$ \\
\hline Nível de Esforço (NE) & $2,84.6,08=17,2672$ \\
\hline Nível de Frustração (NF) & $1,31.4,20=5,5020$ \\
\hline CARGA DA TAREFA & $84,8135 / 15=\mathbf{5 , 6 5 4 2}$ \\
\hline
\end{tabular}

Fonte: Autores (2021).

A carga de trabalho subjetiva média revelada pelos participantes da pesquisa obteve-se o indicador aproximado de 5,65 (cinco pontos e sessenta e cinco centésimos) dentro de uma amplitude se 0 a 10 pontos (régua do formulário), de acordo com o protocolo NASA/TLX.

\subsection{Análise dos dados coletados}

Para o procedimento de avaliação de carga de trabalho subjetiva ou carga informacional neste estudo para visualizar o impacto do Ensino Remoto Emergencial (ERE), foram necessários os cálculos de Taxa, Peso e ajuste para alcançar a Taxa ponderada formatados com base no protocolo NASA/LTX adaptado em apêndice. Para os cálculos ajustados, utilizou-se da multiplicação entre taxa e peso. A taxa ponderada é a soma dos valores ajustados e serve para utilização de comparação entre as três categorias ou indivíduos, de acordo com o TLX. 
A participação foi considerada razoável em consideração aos que obtiveram participação plena, com um índice de $52 \%$ ou 73 (setenta e três) dos 142 (cento e quarenta e dois) discentes concluintes.

Deve se destacar que dos 206 (duzentos e seis matriculados) nas nove disciplinas pesquisadas, ofertadas em modelo de Ensino Remoto Emergencial (ERE1 e ERE2) 31\% ou 64 (sessenta e quatro) discentes abandonaram ou não postaram as tarefas que implicava em frequência e aproveitamento.

Para melhor visualização do método apresentam-se a seguir, graficamente, as taxas das exigências e níveis, e os pesos dos critérios (Taxas) nos gráficos 1 e 2, bem como a Carga de Trabalho Subjetiva ou Informacional atingida.

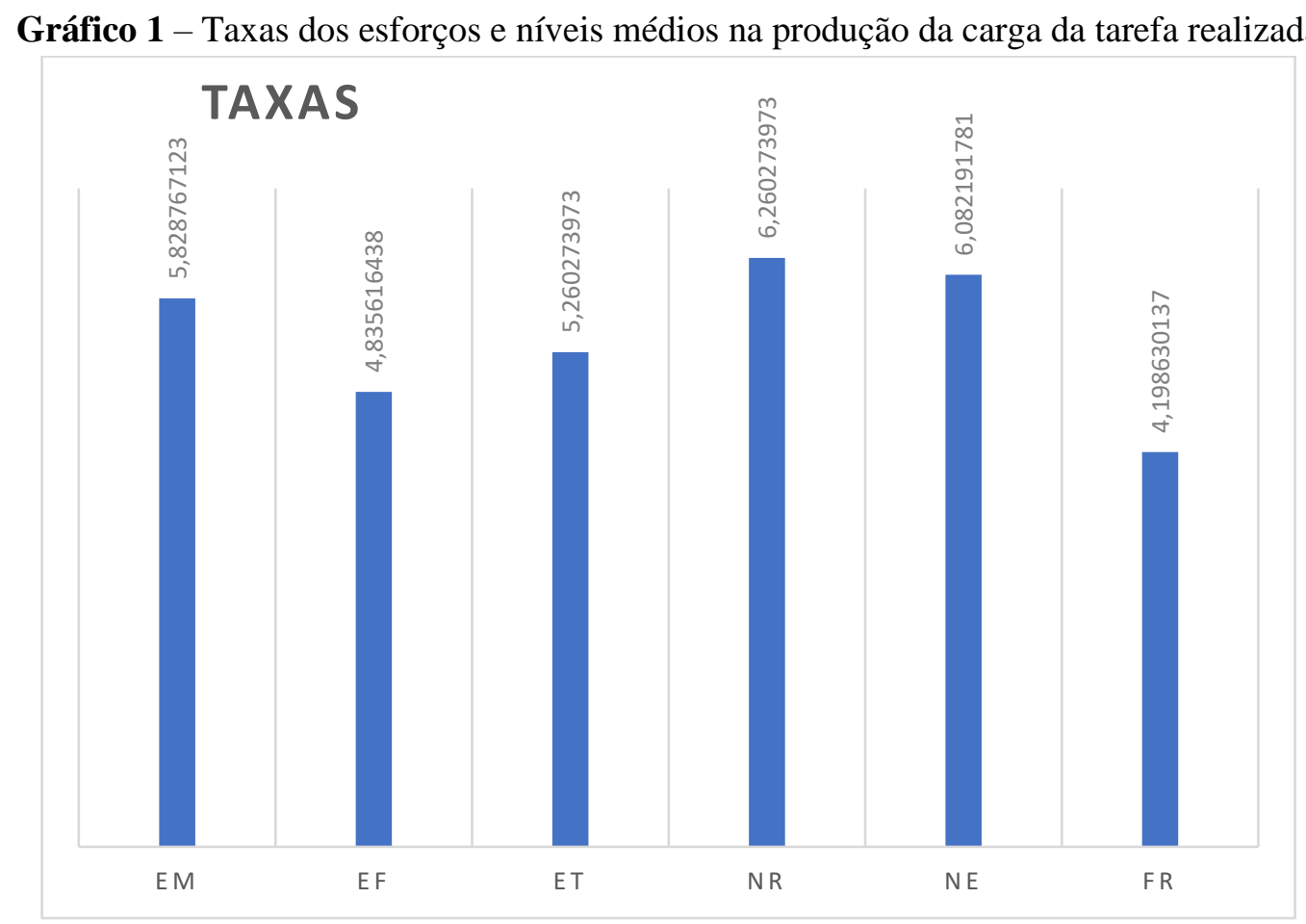

Fonte: Autores (2021).

Em análise das seis subescalas, sendo 3 demandas impostas ao sujeito temos que a Demanda ou Exigência Mental (EM) a qual pergunta o grau de atividade mental, de concentração e de atenção são exigidos para a execução da tarefa nas disciplinas, apresentou com indicador aproximado de 5,82, considerado como médio, para a Demanda ou Exigência Temporal (ET) também considerada média com indicador aproximando de 5,26 ao perguntar quanto de pressão sentiu com relação ao ritmo cobrado para a execução dessa tarefa e pôr fim a Demanda ou Exigência Física (EF), considerada baixa com indicador de aproximado de 4,83 em relação a quanto de atividade física a tarefa exigia. 
Para as 3 dimensões referem-se à níveis interação entre sujeito e tarefa, obteve-se que o Desempenho ou Realização (ND) ao perguntar sobre a percepção de sucesso em na realização das metas obteve-se o maior indicador com aproximadamente 6,26, considerado médio superior. Para o Esforço (NE) o indicador também foi considerado médio superior com indicador aproximado de 6.08 ao ser perguntado sobre quantidade de esforço total (mental+físico) você precisou aplicar para realizar sua tarefa. Em conclusão do das dimensões o que obteve o menor indicador foi o nível de Frustração (NF) com indicador aproximado de 4,20 após perguntar sobre o sofrimento, insegurança, desencorajamento, irritação, desconforto e estresse na realização as metas da sua tarefa.

Gráfico 2 - Pesos dos esforços e nível médios na produção da carga de trabalho

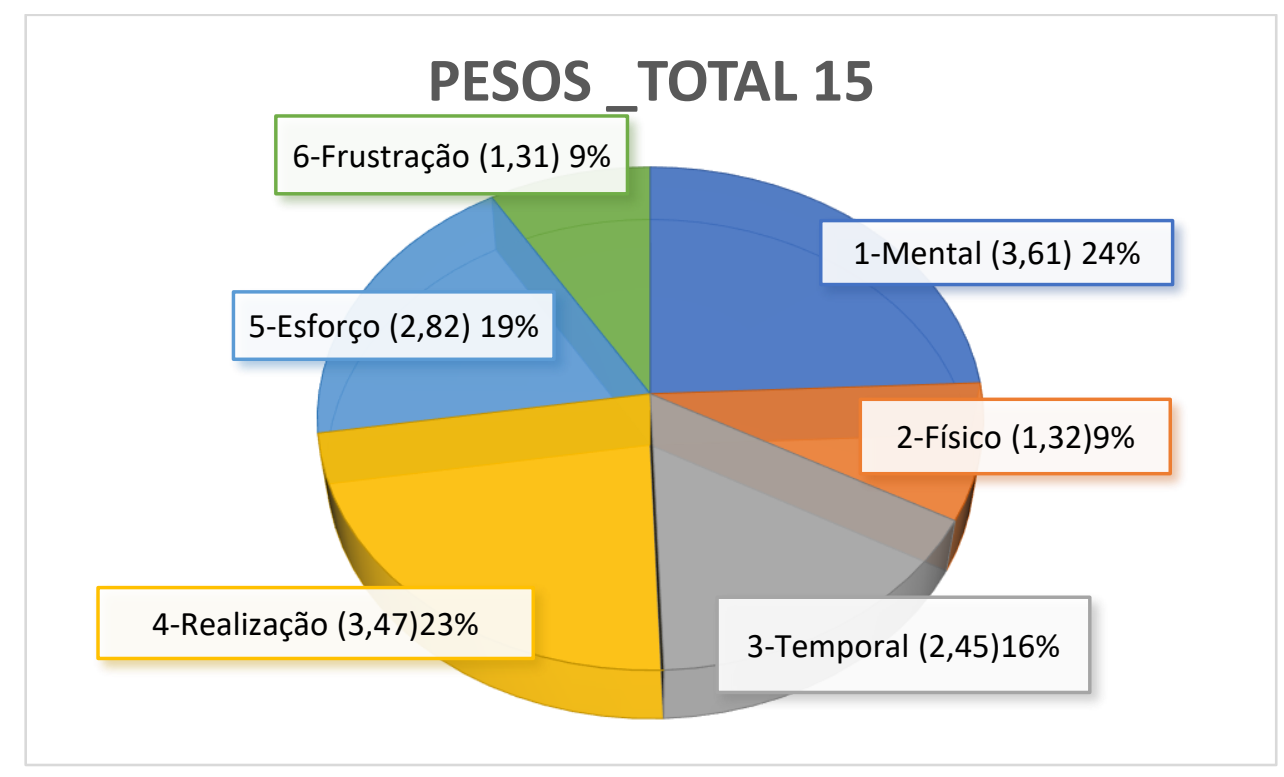

Fonte: Autores (2021).

Os pesos das demandas tem a finalidade de atribuir o grau de importação de cada esforços e níveis em relação a composição da carga subjetiva de trabalho da disciplina, a qual foi realizada com a comparação par a par, obtendo quinze comparações, indicado o cada de cada na composição da carga para a população analisada.

O resultado demostrou que o nível de frustração e a exigência física na realização das tarefas tem o menor peso, sendo cada uma responsável por 9\%. O nível de esforço e exigência temporal no comprimento da disciplina obteve um grau de importância moderado, com 19\% e 16\% respectivamente e os grandes motivadores ou desmotivadores foram nível de realização ou desempenho e a exigência mental com $23 \%$ e $24 \%$ respectivamente. 
Em conclusão a média da carga subjetiva de trabalho empregada ao acadêmico que cursam as disciplinas em Ensino Remoto Emergencial foi de 5,65 (cinco pontos e sessenta e cinco centésimos) dentro de uma amplitude se 0 a 10 pontos, o que gera um conceito mediano ou que a carga para o cumprimento das disciplinas pelos participantes fora considerada razoável.

\section{CONSIDERAÇÕES FINAIS}

Este teve como objetivo geral de mensurar a carga de trabalho empregada ao acadêmico que cursam alguma disciplina em Ensino Remoto Emergencial de uma IFES. O Impacto do Ensino Remoto Emergencial na carga de trabalho dos discentes de um curso de Instituição Federal de Educação Superior, ficou delimitado para nove disciplinas o curso de Gestão da Informação de uma Universidade federal do sul do Brasil com 73 (setenta e três) participantes durante a oferta do Ensino Emergencial Remoto do primeiro e segundo semestre de 2020 em virtude da situação atual imposta trazidas pela pandemia do COVID-19 ou SARS-CoV-2 e a paralização da educação presencial.

Não se confirmando uma elevação considerável da carga subjetiva de trabalho dos discentes participantes, levantada através do protocolo NASA-LTX adaptado, no valor de 5,65 (cinco pontos e sessenta e cinco centésimos), a qual foi considerada moderada ou razoável a carga de trabalho subjetiva ou informacional para as disciplinas ofertadas e pesquisadas, revelando um planejamento equilibrado da disciplina para o curso e um preparo dos discentes frente a esta modalidade de ensino.

A contribuição deste está na quantidade de informações levantadas frente o atual cenário considerando as suas limitações estabelecidas, que podem auxiliar futuros projetos nessa linha de pesquisa, pois poderão focar em aspectos que não foram abordados nesse estudo ou que não foram considerados quantitativamente, como o levantamento de carga cognitiva comparativamente a mesma disciplina na modalidade presencial, outros termos de busca ou uma nova estratégica para incorporar os discentes desistentes.

\section{REFERÊNCIAS}


ALBAGLI, Sarita. Território e territorialidade. Territórios em movimento: cultura e identidade como estratégia de inserção competitiva. Relume Dumará (Online), Rio de Janeiro, p. 23-69, 2004. Disponível em: <http://inspirebr.com.br/uploads/midiateca/ d64c55dfd943251ede2b6330035a5994. pdf>. Acesso:14 jun. 2018.

ALCHIERI, João Carlos e CRUZ, Roberto Moraes (org). Avaliação psicológica: conceitos, métodos e instrumentos. São Paulo: Ed. Casa do Psicólogo, 2003.

ANDES. SINDICATO NACIONAL DOS DOCENTES DAS INSTITUIÇÕES DE ENSINO SUPERIOR. Cartilha Projeto do capital para a educação: $O$ ensino remoto e o desmonte do trabalho docente. Vol. 4, ANDES-SN: Brasília, set. 2020. Disponível em: <https://www.andes.org.br/diretorios/files/renata/setembro/cartilha\%20ensino\% 20remoto.pdf> Acesso em 30 dez 2021.

ANTÓNIO MOREIRA, José; SCHLEMMER, Eliane. Por um novo conceito e paradigma de educação digital online. Revista UFG, v. 20, n. 26, 13 maio 2020. Disponível em: https://www.revistas.ufg.br/ revistaufg/article/view/63438. Acesso em: 14 set. 2020 .

ASSOCIAÇÃO BRASILEIRA DE NORMAS TÉCNICAS (ABNT). ISO/NBR 10075-1: Princípios ergonômicos relacionados à carga mental: Termos e definições gerais. Rio de Janeiro, 2017.

BOHADANA, Estrella \& VALLE, Lílian do. O quem da educação a distância. Revista Brasileira de Educação (Online), Rio de Janeiro, v. 14 n. 42, p.-551-606, SetDez. 2009. Disponível em:〈https://www.scielo.br/pdf/rbedu/v14n42/v14n42a11.pdf> Acesso em: 12 jun. 2020.

BRASIL. Portal MEC: Legislação de Educação à Distância. Disponível em:< http://portal.mec.gov.br/expansao-da-rede-federal/193-secretarias-112877938/seededucacao-a-distancia-96734370/12778-legislacao-de-educacao-a-distancia>. Acesso em: 18 jun. 2020.

CAJUEIRO, R. L. P. Manual para elaboração de trabalhos acadêmicos: guia prático do estudante. 3. ed., Petrópolis: Vozes, 2015.

CAÑAS, Jose; WAERNS, Yvone. Ergonomia Cognitiva: Aspectos psicologicos de La interacion de lãs personas com La tecnologia de La informacion. Madrid: Ed. Panamericana, 2001. 
CARMO, R. de O. S.; FRANCO, A. P. Da docência presencial à docência online: aprendizagens de professores universitários na educação a distância. Educação em Revista, Belo Horizonte, v. 35, 2019. DOI: https://doi.org/10.1590/0102-4698210399

CHIAVENATO, Idalberto, Introdução à teoria geral da administração: uma visão abrangente da moderna administração das organizações. 7. ed. rev. e atual. - Rio de Janeiro: Elsevier, 2003.

COELHO, Willyans Garcia \& TEDESCO, Patricia Cabral de Azevedo Restelli. A percepção do outro no ambiente virtual de aprendizagem. Revista Brasileira de Educação (Online), Rio de Janeiro, v. 22, n. 70, p.609-624, Jul-Set 2017. Disponível em: <https://doi.org/10.1590/s1413-24782017227031> Acesso em: 15 jun 2020.

CRUZ, Roberto M. \& FRUTUOSO, Joselma T. Mensuração da carga de trabalho e sua relação com a saúde do trabalhador. Revista Brasileira de Medicina do Trabalho (Online), Belo Horizonte, vol. 3, n. 1, p. 29-36, Jan-Jun 2005. Disponível em: $<$ http://rbmt.org.br/details/166/pt-BR/mensuracao-da-carga-de-trabalho-e-sua-relacaocom-a-saude-do-trabalhador >Acesso em: 02 set 2009.

FACHIN, O. Fundamentos de metodologia. São Paulo: Saraiva, 2006.

FERNANDES, Wendel Simões et al. Educação a distância: principais aspectos positivos e negativos. Revista Brasileira de Educação e Saúde(Online), Pombal/PB, v. 8, n. 4, p. 41-47, Out-Dez 2018. Disponível em: <https://editoraverde.org/gvaa.com.br/ revista/index.php/REBES/article/view/6095> Acesso em: 13 mar 2019.

GIL, Antônio Carlos. Como elaborar projetos de pesquisa. 6. ed., São Paulo: Atlas, 2017.

GIOLO, Jaime. Educação a Distância no Brasil: a expansão vertiginosa. Revista Brasileira de Política e Administração da Educação (Online), UFRGS/Porto Alegre, v. 34, n. 1, p. 073 - 097, Jan-Abr 2018. Disponível em: <https://seer.ufrgs.br/rbpae/article/ view/82465> Acesso em: 5 mai 2020.

HART, S. G. e STAVELAND, L. E. Development of NASA-TLX (Task Load Index): Results of empirical and theoretical research. Advances in Psychology: Human Mental Workload (Online), Amsterdam: North- Holland, vol. 52, p. 139 - 183, 1988. Disponível em: <https://doi.org/10.1016/S0166-4115(08)62386-9> Acesso em: 10 out 2005. 
HAVIARAS, Mariana. Proposta de formação de professores para o uso de tecnologias educacionais. Intersaberes, Curitiba, v. 15. n. 36, 2020. DOI: https://doi.org/10.22169/revint.v15i35.1762.

HOUAISS, Antonio et all. Dicionário HOUAISS da língua portuguesa. Rio de Janeiro: Objetiva, 2001.

LIMA, C. L; QUEIROZ, E. C. S. B; SANT'ANNA, G. J. A Relação entre Concentração e Aprendizagem: O Uso de TIC para a aprendizagem do aprender. Revista Científica Multidisciplinar Núcleo do Conhecimento. Ano 03, Ed. 11, v. 05, p. 161 186, nov. 2018.

LUDOVICO, Francieli Motter et al. COVID-19: desafios dos docentes na linha de frente da educação. Interfaces Científicas. Aracaju, v.10, n.1, p. 58-74, número temático $-2020$.

MANUAL DO NASA-TLX. NASA Ames Research. Califórnia: EUA, 1986. Disponível em: <https://ntrs.nasa.gov/archive/nasa/casi.ntrs.nasa.gov/20000021488.pdf $>$ Acesso em : 12 ago 2005.

MENEZES, Wladimir Jatobá de. Tecnologia, Organização do Trabalho e Custo Cognitivo: Ação Ergonômica em um Núcleo de Segurança da Informação. Revista Subjetividades (Online), Fortaleza, 16(2), p. 117-131, agosto 2016. Disponível em:<http://dx.doi.org/10.5020/23590777.16.2.117-131> Acesso em: 01 abr 2019.

MONDINI, Vanessa Edy Dagnoni \& DOMINGUES, Maria José Carvalho de Souza. Gestão da retenção de alunos em cursos on-line sob a perspectiva da aceitação da tecnologia. Revista Brasileira de Educação (Online), Rio de Janeiro, v. 23, p.01-29, Set 2018. Disponível em: <https://doi.org/10.1590/s1413-24782018230050> Acesso em: 30 jun 2020.

NANTES, Eliza Adriana Sheuer et al. Percepções de professores da educação a distância sobre a tecnologia e sua aplicabilidade pedagógica. Revista Conhecimento (Online), FEEVALE: Novo Hamburgo/RS, ano 11, v. 2, p.150-170, Mai-Ago 2019. Disponível em: <https://periodicos.feevale.br/seer/index.php/revistaconhecimento online/article/view/1592> Acesso em: 01 jul 2020.

OLIVEIRA, Maria Marly de. Como fazer pesquisa qualitativa. $7^{\mathrm{a}}$ ed., ver e amp., $1^{\text {a }}$ reimp., Petrópolis: Vozes, 2018. 
OLIVEIRA, Sidmar da Silva et al. Educar na incerteza e na urgência: implicações do ensino remoto ao fazer docente e a reinvenção da sala de aula. Interfaces Científicas. Aracaju, v.10, n.1, p. 25-40, número temático - 2020.

PAULA, Alisson S. N. Educação a Distância e a Expansão Mercantil do Ensino Superior Brasileiro. TrabalhoNecessário (Online), UFF/Niterói, Ano 14, n. 23, p. 94 117, 2016. Disponível em:<https://periodicos.uff.br/trabalhonecessario/article/ view/9603>Acesso em: 17 jul 2019.

RIEDNER, Daiani Damm Tonetto \& BATISTA, Erlinda Martins. Trajetória da Educação a Distância na UFMS: Desafios para a Institucionalização. Revista Intersaberes (Online), UNINTER/Curitiba, vol.13, n.29, p. 230-239, Mai-Ago 2018. Disponível em: <https://www.uninter.com/intersaberes/index.php/revista/article/ view/1426> Acesso em: 02 set 2020.

SANTANA, Ana C. A. \& GIRAFFA, Lucia M. M. Educação a Distância a a (Re)Leitura do Esclarecimento de Kant. Interfaces Científicas - Educação (Online), Aracaju, v.7, n.1, p. 129 - 136, Out 2018. Disponível em: <https://periodicos.set.edu.br/ index.php/educacao/article/view/3217> Acesso em: 01 ago 2019.

SANTO, E. do E.; DIAS-TRINDADE, S. Educação a distância e educação remota emergencial: Convergências e divergências. Dialética e Realidade, Curitiba, nov. 2020. Disponível em: https://www.researchgate.net/publication/346605319_Educacao_a_ distancia_e_educacao_remota_emergencial_convergencias_e_divergencias. Acesso em: 09 fev. 2020.

SANTOS, Rodrigo O.; MOSER, Alvino \& LIMA, Thereza. Hipertexto como mediador pedagógico. Revista Diálogo Educacional (Online), Curitiba, v. 19, n. 61, p. 792-808, Abr-Jun 2019. Disponível em: <http://dx.doi.org/10.7213/1981416X.19.061.AO04 > Acesso em: 15 fev 2020

SCHULENBURG, Roy \& PEZZINI, Marina Ramos. Sistematização de conceitos ergonômicos e semióticos para projetos de interfaces gráficas do usuário. Projetiva (Online), Londrina, v.4, n.1, p.199-218, Jan-Jun 2013. Disponível em: <http://dx.doi.org/10.5433/2236-2207.2013v4n1p199> Acesso em: 02 nov 2017.

SILVA FILHO, José Luiz Fonseca et al. Ergonomia cognitiva em ambientes virtuais de aprendizagem: uma análise da interface humano - computador (IHC) do 
sistema polvo. In: XXVIII Encontro Nacional de Engenharia de Produção; A integração de cadeias produtivas com a abordagem da manufatura sustentável, 28 ed., Rio de Janeiro, 13 a 16 de out 2008. Anais ENEGEP: ABEPRO, 2008. Disponível em: <http://www.abepro.org.br/biblioteca/enegep2008_tn_stp_069_490_11885.pdf> Acesso em: 12 jul 2019.

SILVA, Tiago Machado e. Carga de trabalho mental: análise crítica dos métodos de avaliação. Orientador: Sergio Luiz Ribas Pessoa, 2018. 233 f. Dissertação (Mestrado do Programa de Pós-Graduação em Engenharia de Produção e Sistemas) Universidade Tecnológica Federal do Paraná, Pato Branco/ PR. Disponível em: <http://repositorio.utfpr.edu.br/jspui/bitstream/1/3587/1/PB_PPGEPS_M_Silva\%2C\%2 0Tiago\%20Machado\%20e_2018.pdf> Acesso em: 29 jun 2020.

SOUZA, Nelson Pinheiro Coelho de. Teoria da carga cognitiva: origem, desenvolvimento e diretrizes aplicáveis ao processo ensino-aprendizagem. Orientadora: Marisa Rosâni Abreu da Silveira, 2010. 173 f. Dissertação (Mestrado do Programa de Pós-Graduação em Ciências e Matemáticas) -Universidade Federal do ParáInstituto de Educação Matemática e Científica, Belém. Disponível em: <https://www.academia.edu/7195870/Teoria_da_Carga_Cognitiva_origem_desenvolvi mento_e_diretrizes_aplic\%C3\%A1veis_ao_processo_ensino-aprendizagem > Acesso em: 03 jul 2020.

VELOSO, Maristela Midlej Silva de Araujo \& BONILLA, Maria Helena Silveira. O professor e a autoria em tempos de cibercultura: a rede da criação dos atos de currículo. Revista Brasileira de Educação (Online), Rio de Janeiro, v. 23, p.1-23, Mai 2018. Disponível em: <https://doi.org/10.1590/s1413-24782018230026> Acesso em: 03 jul 2020.

WISNER, A. A inteligência do trabalho. São Paulo: Unesp/Fundacentro, 1994.

YULIANI, E.N.S and TAMBUNAN, E.B.M. Reduce workload of security officers using NASA-LTX, SOFI, Heart Rate and Energy Expenditure Method. In: International Conference on Design, Engineering and Computer Sciences, Jakarta, nov 2018. IOP Conference Series: Materials Science and Engineering, Jakarta, vol 453, nov 2018. Disponível em: <https://iopscience.iop.org/article/10.1088/1757-899X/453/1/012065> Acesso em; 27 jul 2020. 
ZAMBRANO, Jimmy. Enseñar considerando la carga mental del aprendizaje: la teoria de la carga cognitiva. In: Conference: IV Congreso Internacional de Ciencias Pedagógicas de Ecuador, At Guayaquil, April 2018. Memorias del cuarto Congreso Internacional de Ciencias Pedagógicas de Ecuador La formación y superación del docente: "desafíos para el cambio de la educación en el siglo XXI", Guayaquil, abr 2018. p. 1609-1619. Disponível em: <https://dialnet.unirioja.es/servlet/articulo?codigo $=7220572>$ Acesso em: 29 jun 2020 . 


\section{APÊNDICE}

Descrição das exigências e limites na escala de avaliação de carga mental Folha de escala de taxa Fonte: NASA-TLX MANUAL, 1986

Assinale com um (X) na escala encontrada abaixo (régua) de cada título apresentada e descrita, segundo a sua percepção sobre suas atividades e avaliações realizadas na disciplina XXX (SIN YYY)

\begin{tabular}{|c|c|c|}
\hline Título & Limites & Descrição \\
\hline Exigência Mental & Baixo/Alto & $\begin{array}{l}\text { Quanto de atividade mental, de concentração e de atenção são exigidos para a execução da } \\
\text { tarefa (exemplo: pensando, decidindo, calculando, lembrando, pesquisando)? } \\
\text { A tarefa é fácil, simples, alcançou sem dificuldade o objetivo exato? (indica LIMITE BAIXO } \\
\text { na escala); ou foi difícil, complexa, exigiu muito esforço mental para tentar alcançar um } \\
\text { objetivo? (indica LIMITE ALTO na escala). }\end{array}$ \\
\hline \multicolumn{3}{|l|}{ Exigência Mental } \\
\hline Exigência Física & Baixo/Alto & $\begin{array}{l}\text { Quanto de atividade física a tarefa exige (ex.: empurrando, puxando, virando, controlando, } \\
\text { mexendo)? } \\
\text { A tarefa é leve, lenta, facilmente realizada e tranquila? (indica LIMITE BAIXO na escala); } \\
\text { ou é pesada, rápida, vigorosa e agitada? (indica LIMITE ALTO na escala). }\end{array}$ \\
\hline \multicolumn{3}{|l|}{ Exigência Física } \\
\hline Exigência Temporal & Baixo/Alto & $\begin{array}{l}\text { Quanto de pressão de tempo você sofreu com relação ao tamanho da tarefa pelo tempo para } \\
\text { executá-la? Quanta pressão você sentiu com relação ao ritmo cobrado para a execução dessa } \\
\text { tarefa? (ex.; proporção entre o horário de trabalho e o tamanho ou complexidade da tarefa, } \\
\text { prazo do serviço encomendado) } \\
\text { O ritmo de trabalho é lento e tranquilo? (indica LIMITE BAIXO na escala); ou é frenético? } \\
\text { (indica LIMITE ALTO na escala) }\end{array}$ \\
\hline \multicolumn{3}{|c|}{$\begin{array}{l}\text { Exigência Temporal } \\
\text { Alta }\end{array}$} \\
\hline Nível de Realização & Alto/Baixo & $\begin{array}{l}\text { Quanto sucesso você acha que tem realizando as metas da sua tarefa? (ex.: satisfação, } \\
\text { reconhecimento) } \\
\text { Você fica muito satisfeito e é elogiado quando você alcança as metas? (indica LIMITE ALTO } \\
\text { na escala); ou você fica pouco satisfeito e quase ninguém nota o seu trabalho? (indica LIMITE } \\
\text { BAIXO na escala) }\end{array}$ \\
\hline \multicolumn{3}{|c|}{ Nível de Realização } \\
\hline Nível de Esforço & Baixo/Alto & $\begin{array}{l}\text { Que quantidade de esforço total (mental + físico) você precisou aplicar para realizar sua } \\
\text { tarefa? (ex.: concentração, força muscular, raciocínio, destreza). } \\
\text { Para que a execução da sua tarefa seja desempenhada com sucesso é necessária concentração } \\
\text { superficial, força muscular leve, raciocínio simples, pouca destreza? (indica LIMITE BAIXO } \\
\text { na escala; ou é necessária concentração profunda, força muscular intensa, raciocínio } \\
\text { complexo e muita destreza? (indica LIMITE ALTO) }\end{array}$ \\
\hline \multicolumn{3}{|l|}{ Nível de Esforço } \\
\hline Nível de Frustração & Baixo/Alto & $\begin{array}{l}\text { Quanto sofrimento você acha que tem realizando as metas da sua tarefa? (ex.: insegurança, } \\
\text { desencorajamento, irritação, desconforto e estresse). } \\
\text { Você se sente seguro, contente e tranquilo quando realiza a sua tarefa? (indica LIMITE } \\
\text { BAIXO na escala); ou pelo contrário, inseguro, desencorajado, irritado, incomodado e } \\
\text { estressado? (indica LIMITE ALTO na escala) }\end{array}$ \\
\hline $\begin{array}{l}\text { Nível de Frustra } \\
\text { Alta }\end{array}$ & & $\perp$ \\
\hline
\end{tabular}

APENDICE - PROTOCOLO ADAPTADO PELOS AUTORES.

FONTE: NASA-TLX MANUAL, 1986. 


\section{Folha de pesos}

Agora que você apresentou sua percepção sobre os níveis e exigências, que a disciplina de XXX (SINYYY) contém, assinale com um círculo no quadro abaixo, em uma comparação par a par, a importância que um item tem em relação ao outro. Serão 15 respostas, pois temos uma combinação de 6 itens 2 a 2, gerando 15 comparações e consequente uma resposta. Caso, você acredite que as duas na comparação tem o mesmo grau de importância, opte por apenas uma. Não deixe em branco e não marque as duas nos quadros comparativos abaixo.

\begin{tabular}{|c|c|c|}
\hline $\begin{array}{c}\text { NÍVEL DE ESFORÇO } \\
\text { OU } \\
\text { NÍVEL DE } \\
\text { REALIZAÇÃO }\end{array}$ & $\begin{array}{c}\text { EXIGÊNCIA TEMPORAL } \\
\text { OU } \\
\text { NÍVEL DE } \\
\text { FRUSTRAÇÃO }\end{array}$ & $\begin{array}{c}\text { NÍVEL DE } \\
\text { REALIZAÇÃO } \\
\text { OU } \\
\text { EXIGÊNCIA TEMPORAL }\end{array}$ \\
\hline $\begin{array}{c}\text { EXIGÊNCIA TEMPORAL } \\
\text { OU } \\
\text { NÍVEL DE ESFORÇO }\end{array}$ & $\begin{array}{c}\text { EXIGÊNCIA FÍSICA } \\
\text { OU } \\
\text { NÍVEL DE } \\
\text { FRUSTRAÇÃO }\end{array}$ & $\begin{array}{l}\text { EXIGÊNCIA MENTAL } \\
\text { OU } \\
\text { NÍVEL DE ESFORÇO }\end{array}$ \\
\hline $\begin{array}{c}\text { NÍVEL DE } \\
\text { REALIZAÇÃO } \\
\text { OU } \\
\text { NÍVEL DE } \\
\text { FRUSTRAÇÃO }\end{array}$ & $\begin{array}{c}\text { EXIGÊNCIA FÍSICA } \\
\text { OU } \\
\text { EXIGÊNCIA TEMPORAL }\end{array}$ & $\begin{array}{l}\text { EXIGÊNCIA MENTAL } \\
\text { OU } \\
\text { EXIGÊNCIA FÍSICA }\end{array}$ \\
\hline $\begin{array}{c}\text { EXIGÊNCIA FÍSICA } \\
\text { OU } \\
\text { NÍVEL DE } \\
\text { REALIZAÇÃO }\end{array}$ & $\begin{array}{c}\text { EXIGÊNCIA TEMPORAL } \\
\text { OU } \\
\text { EXIGÊNCIA MENTAL }\end{array}$ & $\begin{array}{l}\text { NÍVEL DE ESFORÇO } \\
\text { OU } \\
\text { EXIGÊNCIA FÍSICA }\end{array}$ \\
\hline $\begin{array}{c}\text { NÍVEL DE } \\
\text { FRUSTRAÇÃO } \\
\text { OU } \\
\text { NÍVEL DE ESFORÇO }\end{array}$ & $\begin{array}{c}\text { NÍVEL DE } \\
\text { REALIZAÇÃO } \\
\text { OU } \\
\text { EXIGÊNCIA MENTAL }\end{array}$ & $\begin{array}{c}\text { NÍVEL DE } \\
\text { FRUSTRAÇÃO } \\
\text { OU } \\
\text { EXIGÊNCIA MENTAL }\end{array}$ \\
\hline
\end{tabular}

Fonte: NASA-TLX MANUAL, 1986.

Recebido em: 12 de Abril de 2021.

Aceito em: 20 de Abril de 2021. 